\title{
The fitness cost to females of exposure to males does not depend on water availability in seed beetles
}

Maider Iglesias-Carrasco ${ }^{1 *}$, Gizem Bilgin ${ }^{1}$, Michael D. Jennions ${ }^{1}$ and Megan L. Head ${ }^{1}$

1 Division of Evolution, Ecology and Genetics. Research School of Biology. Australian National University.

Canberra, Australian Capital Territory, Australia.

*miglesias15@gmail.com. 0415387638. Division of Evolution, Ecology \& Genetics, Research School of Biology, Australian National University, Canberra, ACT, 0200

\section{ABSTRACT:}

Access to multiple males can benefit a female because it increases her fecundity and/or the performance of her offspring due to males providing material benefits and/or genetic gains from polyandry (i.e. cryptic female choice). However, the presence of more males can also impose costs on females that arise from an elevated mating rate and/or increased harassment.

Understanding how different environments influence the relative magnitude of these costs and benefits is important to understanding how factors that affect the rate of male-female interactions, such as the sex ratio and density of each sex, will alter the evolution of traits due to shifts in the magnitude of sexual conflict and sexual selection. Here we explored whether the net fitness of female seed beetles (Callosobruchus maculatus) is affected by breeding in either a dry or wet environment when housed with differing numbers of males (either none, one or four). Consistent with costly male harassment, females housed with four males laid significantly fewer eggs than those housed alone or with a single male. However, there was no significant effect of the number of males on a female's egg laying rate, her lifespan, larval development rate or the egg-adult survival of offspring. Although females in the wet environment lived significantly longer, the decline in the rate of egg laying and egg-adult survival with maternal age was stronger in the wet than the dry environment. Crucially, there was no evidence that water availability affects the net fitness cost to females of being exposed to more males.

Keywords: Callosobruchus maculatus, costs of mating, fitness, sexual harassment, polyandry. 
Reproductive interactions between males and females always come with the benefit to females of providing access to sperm that is needed for offspring production. However, the presence of several males can also come at a cost for females. In most species the optimal number of matings is lower for females than males (Arnqvist \& Nilsson, 2000). This generates sexual conflict over mating and can lead to male harassment (i.e. repeated unsuccessful mating attempts by coercive males), which increases the costs of interacting with males (e.g. reduced feeding opportunities, increased physical injury; Bateman, Ferguson, \& Yetman, 2006; Rönn, Katvala, \& Arnqvist, 2006; Takahashi \& Watanabe, 2010). In consequence, females might sometimes opt to mate simply to decrease harassment (i.e. convenience polyandry) (Blyth \& Gilburn, 2006; Thornhill \& Alcock, 1983). Although there are potential gains of mating multiply for females, due to both direct benefits (e.g. greater access to male services and resources, Hasson \& Stone, 2009; Townsend, Clark, \& McGowan, 2010) and indirect benefits (e.g. higher genetic quality offspring, or the use of compatible sperm to elevate offspring viability, Jennions \& Petrie, 2000; Tregenza \& Wedell, 2002), mating can impose direct costs that accumulate with each successive mating (Crudgington \& Siva-Jothy, 2000; Fedorka, Zuk, \& Mousseau, 2004; Wigby \& Chapman, 2005). Consequently, the degree to which females increase their mating rate when more males are present is likely to depend on balancing the costs of resisting male mating attempts with the shift in the net fitness effects of each successive mating. How the various costs and benefits balance out to influence female fitness is important in determining what type of mating systems and reproductive behaviour evolve.

To date, few studies have tested whether the fitness consequences for females of increased interactions with males varies because the local environment affects the relative strength of sexual selection or sexual conflict arising from additional matings and/or resisting more mating attempts (Sih, Montiglio, Wey, \& Fogarty, 2017; Smith, 2007). Female mating 
decisions are likely to be plastic if the fitness consequences of additional matings are contextdependent (Rosenthal, 2017). For example, population density might influence the optimal mating strategy of females to acquire direct and indirect benefits (Kokko \& Rankin, 2006), such that female mating preferences are density-dependent (Rosenthal, 2017; Welch, 2003). At low densities females are predicted to be less selective due, in part, to reduced mate availability and the increased time and energy costs of locating mates (Hutchinson \& Halupka, 2004; Kokko \& Mappes, 2005). Higher densities will, however, tend to increase the number of male mating attempts. This could lead to either a reduction in female willingness to remate (e.g. Martin \& Hosken, 2003) due to the increased costs of excess mating, or to an increase in female mating rate to lower the short-term rate of harassment (e.g. Rowe et al., 1994).

The environment could also affect the magnitude of the direct benefits that females receive from each mating (e.g. the quantity of beneficial substances transferred in ejaculates, such as nutrients and hormonal triggers that elevate egg production; Arnqvist \& Nilsson, 2000; Yamane et al., 2015). For example, low food availability might decrease male body condition and reduce ejaculate size and composition (Perry \& Rowe, 2010; Polak et al., 2017, IglesiasCarrasco et al., in review), and thereby lower the net direct benefits of mating. Similarly, females in an environment with greater access to food have been shown to remate less often due to the reduced value of obtaining mating gifts from males (Toft \& Albo, 2015). Despite the likely role of the environment in determining the net outcome of female mating decisions, relatively few studies have asked how environmental changes affect male-female interactions due to the potential for correlated changes in both male harassment and the benefits of additional matings (but see Edvardsson 2007).

The seed beetle Callosobruchus maculatus is an ideal model species to investigate the fitness consequences for females of interacting with different numbers of males. Although females are often polyandrous the direct benefits of mating multiply are subtle (e.g. no nuptial 
gifts). Previous studies in C. maculatus have yielded mixed results that make it difficult to predict the net fitness effect on females of more males being present, due to the combination of both direct and indirect benefits of additional matings, alongside the cumulative costs of remating. For example, there is evidence that polyandrous females lay more eggs than those mated to a single male (even after controlling for the number of matings) (Eady, Wilson, \& Jackson, 2000), possibly due to cryptic female choice. Intriguingly, there are also potential direct benefits of mating. Several studies have suggested that fecundity benefits could be attributed to nutrients and water in ejaculates (Eady, Hamilton, \& Lyons, 2007; Savalli \& Fox, 1999; Ursprung, Den Hollander, \& Gwynne, 2009). C. maculatus are a pest of stored legumes, and live in an environment where there is little or no access to water or food for adult beetles. Water is therefore expected to be a limiting resource for females that constrains their reproductive output and life span. Males of $C$. maculatus transfer ejaculates that are rich in water (Edvardsson, 2007) so, if male ejaculates are the only water resource available to adult females, we might expect the net benefits of remating to sometimes outweigh the costs, thereby increasing the mating propensity of females. However, there are other potential costs of mating that could reduce or eliminate the net benefits of polyandry. The costs of copulation in the seed beetle include traumatic wounding of the female reproductive tract caused by the male aedeagal spines and the transfer of toxic ejaculatory substances (Crudgington \& SivaJothy, 2000; Paul E. Eady et al., 2007; Gay, Eady, Vasudev, Hosken, \& Tregenza, 2009). In addition, the presence of more males leads to greater male harassment that can reduce female lifespan (den Hollander \& Gwynne, 2009). Surprisingly, despite extensive research in $C$. maculatus we still do not know if the environment alters the balance between these putative costs and benefits of mating and therefore the relative effect of variation in the number of males that females encounter on their fitness (but see Edvardsson 2007).

Two previous studies in C. maculatus (Edvardsson, 2007; Ursprung et al., 2009) have demonstrated that water availability increases a female's life span and fitness, while reducing 
her willingness to remate. These findings suggest that water is a limiting resource for females, who might benefit from the water acquired from male ejaculates. However, if females make use of environmental water this might reduce the advantage of additional matings through the acquisition of water in ejaculates. Here we build on this previous knowledge to test whether breeding in a dry versus wet environment affects the net fitness of females in a manner that depends on how many males they are housed with (i.e. due to the combination of a change in the level of male harassment and the number of mates and/or matings). Access to water in the environment could lower the benefit to a female of gaining water from ejaculates, potentially altering her behaviour and fitness in a manner that depends on the number of males encountered. We predict that: 1) In both dry and wet conditions, females exposed to males

\section{METHODS}

\section{Study species}

The seed beetle Callosobruchus maculatus is a pest species of stored legumes. In this environment adults have no access to food or water and all resources required for adult survival and reproduction are acquired from the host bean during the larval stage (Messina \& Slade, 1997). The seed beetles life-cycle begins with females laying an egg on the surface of a host bean. The hatching larva burrows into the bean and remains inside feeding on it for 3-4 weeks until it emerges as an adult. We used beetles originating from a stock kept at the 
University of Western Australia since 2005 in cultures of $>500$ adults breeding on black-eyed beans (Vigna unguiculata) (Dougherty et al., 2017). This stock was maintained in our lab in cultures of $>500$ beetles at $27 \pm 1^{\circ} \mathrm{C}$ with a 14 :10 light:dark cycle for three generations prior to our experiment. Stock larvae were raised on black-eyed beans and adults were provided with neither food nor water.

Ethical Note

This work followed the ASAB/ABS guidelines for the treatment of animals in

behavioural research. Information about individuals' housing conditions are described below.

Housing conditions, handling and experimental monitoring were all conducted in a way so as to maximize the animals' welfare. We complied with the Australian regulations for experiments on invertebrates. benefits for females of being exposed to different numbers of males we used a $2 \times 3$ experimental design where we manipulated water availability (wet or dry) and the number of males $(0,1$ or 4$)$ housed with a female after an initial single mating to ensure she had sperm. 
an egg, the bean was removed and placed individually in an Eppendorf tube with a pin-hole in the cap for airflow. We repeated this procedure until we had 400 beans each with a single egg. The adults that started to emerge around 21 days later became the focal individuals for our experiment. The eclosion date was recorded and individuals were given $24 \mathrm{~h}$ to attain sexual maturity (Fox, Hickman, Raleigh, \& Mousseau, 1995). We then placed a randomly chosen virgin female with a virgin male in an Eppendorf tube and allowed them to mate. After a single copulation, females were randomly assigned to one of our six treatments.

Females were individually placed in a $60 \mathrm{ml}$ plastic container with approximately 40 mung beans. Water was supplied ad libitum to females in the wet treatment by placing soaked cotton wool in a plastic vial lid, which was refilled every 24 hours. Females have previously been shown to drink water when it is made available in this way (Edvardsson, 2007). Too few males emerged at the same time as females, so for the first 24 hours after copulation (day 1 ), all females were alone in their designated water treatment. For the next three days (day 2, 3, 4), in addition to their corresponding water treatment, females experienced one of the three levels of exposures to males. Females were transferred daily to a new container with approximately 40 mung beans that again, depending on her treatment group, housed either zero, one or four males (drawn from a large stock of previously mated males). On day 5 all males were removed and females remained in their day 4 container in their designated water treatment until death. Female survival was monitored every $24 \mathrm{~h}$ and her lifespan was recorded as the number of days a female survived after her first copulation. We counted the number of eggs laid in each container to measure both egg laying rate (i.e. for days 2 and 3 ) and 'lifetime' egg production (excluding day 1 eggs which were laid prior to exposure to males). Once eggs on beans were counted, we returned the beans to the controlled temperature room and 21 days later we began to check for emerging adults. We recorded the eclosion date of the first emerging offspring per container to estimate development time. Once offspring started to emerge they were counted and removed each day for 10 days. We 
used these data to calculate the percentage of eggs that produced emergent offspring (hereafter 'egg-adult survival').

\section{Statistical analyses}

Females spent the first 24 hours after their initial copulation in their designated water treatment but without any males. Our test for an effect of male presence on female fitness is therefore conservative. Our main aim was to test if and how access to water and exposure to males interact, and we therefore excluded eggs collected on the first day from our analyses.

We tested how water availability and the exposure to males influenced egg laying in two ways: 'lifetime' egg production (i.e. from day 2 onward), and egg laying rate (i.e. eggs/day for day 2 and 3 in the second and third containers respectively). For 'lifetime' egg production we specified a generalized linear model (GLM) with a Quasipoisson error distribution to account for overdispersion. Water availability, level of exposure to males, and their interaction were specified as fixed factors. For egg laying rate we specified a Generalized Linear Mixed Model (GLMM) with a Poisson error distribution. Water availability, level of exposure to males, day (second or third) and all two-way and three-way interactions were specified as fixed factors. We included female identity as a random effect to control for individual variation, and an observation level random effect to correct for overdispersion (Harrison, 2014). Following this correction, our model was underdispersed (dispersion parameter $=0.517$ ).

To determine whether water availability and level of exposure to males influenced egg-adult survival we ran a GLMM with a binomial error distribution using the cbind function (number of adults eclosing; number of unhatched eggs). We treated water availability, level of exposure to males, the day the eggs were collected and all two and three-way interactions as fixed factors. Female identity was treated as a random effect. We constructed a similar model to look at the effects of water availability, level of exposure to males and time since mating on offspring development time, but in this case the best fit model was a GLMM with a Poisson 
error structure. We corrected for overdispersion using an observation level random effect (Harrison, 2014).

We used Cox proportional hazard models (function coxph, R package survival,

Therneau \& Grambsch, 2000) to test if water availability and male exposure affected female survival.

Our general protocol to test whether water availability, level of exposure to males, and day interacted to affect female fitness was to initially include two- and three-way interactions in models. We then re-ran models without these interactions. If their removal did not reduce the model fit (LLR test), we interpreted the main effects from the reduced model. If it did reduce the fit, we interpreted the interactions by looking at the model parameters. All analyses were conducted in R 3.4.

\section{RESULTS}

Model parameter estimates and test statistics are provided in Tables A1-A5 in the Appendix.

Tests for main and interaction effects are presented in the text below.

The number of males a female was exposed to had a significant effect on her lifetime egg production $\left(X^{2}=6.730, d f=2, P=0.035\right.$, Figure 1 a, Table A1). Females exposed to four males laid significantly fewer eggs than those that were alone $(P=0.006)$ or with only one male $(P=$ 0.048). There was, however, no significant difference in the total number of eggs laid by females that were alone or with only one male $(P=0.444)$. Water availability did not affect the total number of eggs laid $\left(X^{2}=0.141, \mathrm{df}=1, P=0.707\right)$, nor did it have a modifying effect on the consequence of a greater level of exposure to males (water*number of males: $X^{2}=4.755$, $\mathrm{df}=2, P=0.093)$. 
The daily egg laying rate decreased over time (Figure 1b, Table A2), and this decline was significantly greater for females with access to water than those without (day*water: $X^{2}=$ $8.461, \mathrm{df}=1, P=0.004)$. No other interactions had a significant effect on the egg laying rate ( water*mating: $X^{2}=2.899, \mathrm{df}=2, P=0.235$; day*number of males: $X^{2}=0.027, \mathrm{df}=4, P=0.987$; water*number of males*day: $\left.X^{2}=2.256, \mathrm{df}=4, P=0.324\right)$.

Egg-adult survival was affected by a three-way interaction between the day of laying, the water treatment and the level of exposure to males $\left(X^{2}=14.535, \mathrm{df}=4, P=0.006\right.$, Figure 2 , Table A3). To investigate this interaction further we analysed each water treatment separately. In the dry environment, the egg-adult survival was lower for the eggs laid on day 4 than for those laid on day 2 or $3\left(X^{2}=32.525, d f=2, P<0.001\right.$, Table 3.1). There was no effect of the exposure to males or any interaction between the day and male exposure (both $P$-values $>$ 0.358). For the wet treatment, how the level of exposure to males affected egg-adult survival depended on the day which eggs were laid (i.e. a two way interaction between male exposure treatment and day: $\left.X^{2}=31.398, \mathrm{df}=4, P<0.001\right)$. On day 2 egg-adult survival decreased when females were exposed with more males, on day 3 egg-adult survival was similar across all male exposure treatments, and on day 4 egg-adult survival was greater when females were exposed to more males.

Larval development time was not affected by the day of egg laying, water availability, the exposure to males or any of their interactions (all $P>0.931$; Figure 3 , Table A4).

Finally, females with access to water lived for significantly longer $\left(X^{2}=46.71, \mathrm{df}=1, P<0.001\right)$, but there was no effect of the level of exposure to males on survival $\left(X^{2}=4.59, \mathrm{df}=2, P=\right.$ 0.100 ) nor did it mediate the effect of access to water (interaction: $X^{2}=0.51, \mathrm{df}=2, P=0.775$ ) (Table A5, Figure 4). 

on females because it had a negative effect on lifetime egg production. There was, however, no detectable effect of the number of males on female lifespan, egg-laying rate, or offspring egg-adult survival or development time. Contrary to our initial prediction that the environment (water availability) would modify the fitness consequences of sexual conflict and sexual selection, while access to water had a significant positive effect on female lifespan, there were no significant interactions between the level of exposure to males and access to water for any of the other four components of fitness that we measured.

Exposure to males and female fitness

We predicted that encountering a greater number of males would negatively affect a female's fitness. Females housed with four males did indeed have lower lifetime egg production than those housed alone or with a single male, but this effect was independent of the water availability treatment. There was no other effect of the number of males present on the other fitness components that we measured, including offspring survival and development rate. The lower fecundity of the females exposed to several males suggests that there are direct costs of mating multiply for females and/or that females suffered from increased male harassment. At present, we are unable to tease apart these two potential costs of an increase in exposure to males, but we discuss the likely role of each. Further, there was no evidence for any paternal effects (i.e. indirect genetic benefits, although non-genetic effects are also possible; see Gasparini, Devigili, \& Pilastro, 2012) of being housed with multiple males on offspring fitness. Introducing males after $24 \mathrm{hrs}$, rather than immediately after an initial mating, could reduce the difference in offspring development time and survival due to different levels

274 of male exposure. However, there was a significant effect of the level of exposure to males on 275 female egg production, so our design was still powerful enough to detect biological meaningful effects of variation in access to males on female fitness. 

during copulation and/or the transfer of toxic ejaculate substances (Chapman, Liddle, Kalb,

Wolfner, \& Partridge, 1995; Crudgington \& Siva-Jothy, 2000; Johnstone \& Keller, 2000; body cavity (Dougherty \& Simmons, 2017; Hotzy, Polak, Rönn, \& Arnqvist, 2012). However, the acquisition of direct material benefits from males upon mating can sometimes compensate for these costs of copulation (Arnqvist \& Nilsson, 2000). For example, mating multiply can increase female life span and fecundity when females only have brief access to males (den Hollander, 2007), suggesting that the male-derived material benefits from mating can sometimes offset any costs of genital injury and toxic effects of ejaculates. In C. maculatus it has been suggested that hydration is the main direct material benefit of mating (Ursprung et al., 2009), which could partly offset costs associated with damage to the female reproductive tract during copulation (Crudgington \& Siva-Jothy, 2000). Our results for female survival partly support these previous findings, in that access to water elevated female lifespan suggesting that water is an important limiting resource for female self-maintenance.

In our study, as always occurs in nature, the opportunity to mate with more males involved greater exposure to males. Male harassment has been suggested to lower female fitness in both vertebrates and invertebrates (e.g. fish: Ojanguren \& Magurran, 2007; damselflies: Takahashi \& Watanabe, 2010; seed beetles: Laurene et al., 2009), related to a range of costs for females including loss of feeding time (Dadda, Pilastro, \& Bisazza, 2005) and higher energy expenditure when resisting male mating attempts (Watson, Arnqvist, \& Stallmann, 1998) that often lead to a reduction in fecundity (Crudgington \& Siva-Jothy, 2000; Eady et al., 2007). In our study a plausible explanation for the lower offspring production of females housed with four males is that it is partly due to greater male harassment and the cost of evading males. Females might also engage in superfluous matings to avoid the costs of 
rejection (i.e. convenience polyandry). This could elevate a female's mating rate such that any direct benefit of re-mating (e.g. hydration) is outweighed by associated costs (e.g. physical damage) that lower her net fecundity. If so, we might expect other components of fitness, such as female survival, to also be affected. This was not the case, however, as exposure to more males did not affect early egg laying rate or female survival.

\section{Effect of water availability and exposure to males on female fitness}

Water has been suggested to be a critical environmental factor driving the mating behaviour of $C$. maculatus, since females gain hydration benefits by mating (Ursprung et al., 2009). In our experiment, both sexes either did or did not have access to water as adults, which mirrors what occurs naturally as there is no habitat segregation by sex. Access to water could influence the relative cost of being exposed to more males in several ways. First, female C. maculatus have a lower propensity to remate after they receive a large ejaculate (Fox, Stillwell, Wallin, \& Hitchcock, 2006; Miyatake \& Matsumura, 2004), which increases their fecundity (Moya-Laraño \& Fox, 2006). Males with access to water might incorporate more into their ejaculates and thereby transfer larger ejaculates. This would make remating less beneficial for females and increase the net cost of being exposed to more males. Second, females with direct access to water have less to gain from the hydration benefit of ejaculates, again reducing the benefits of remating. If females are phenotypically plastic in their mating behaviour, both mechanisms should reduce their propensity to mate multiply, decreasing the number of costly copulations (albeit while simultaneously increasing the absolute material benefits of obtaining more water if they do remate). Fewer copulations and the increased acquisition of useful material in ejaculates should be beneficial for females. In support of the benefit of greater access to water, although we cannot tease apart the importance of the two mentioned mechanisms, we found that adult females with access to water lived significantly 
longer than those without access. Previous studies have also found a fecundity benefit to females provided with water (Edvardsson, 2007; Ursprung et al., 2009).

Unexpectedly, females housed with four males showed a similar reduction in offspring production compared to those maintained alone or with one male regardless of whether or not they had access to water. There was no detectable moderating effect of the environment on the combined effects of male presence on female fitness due to changes in harassment, mating rates and the material benefits of mating. However, a post hoc exploratory analysis (suggested by a reviewer) suggests that there might be an effect of water availability on the fitness cost of exposure to males when only considering females expose to either no male or a single male ( $P=0.036$ for the interaction). Even so, we treat this result with caution because it is based on an unplanned test promoted by the observed trend. Nonetheless, it suggests that the effects of male exposure might be non-linear, which is worth exploring in future studies. In general, we expect changes in the environment to alter the balance between the costs of copulation and harassment, and any benefits of mating (e.g. Plath et al., 2003; Edenbrow et al., 2011; Fox et al., 2006), and thereby affect female behavioural responses to male harassment (e.g. Rowe et al., 1994). Specifically, in seed beetles females with access to water are less inclined to remate than those without access after short-term exposure to males (Edvardsson, 2007; Ursprung et al., 2009), reducing the costs associated with excess copulations. But, to our knowledge, what happens when females are continuously housed and harassed by males has not yet been explored. One possibility is that in a wet environment mating attempts by male $C$. maculatus are more frequent and longer chases ensue due to a greater reluctance of females to mate. This might increase disturbance of females during oviposition and induce females to engage in superfluous matings thereby ameliorating the aforementioned benefits to females of greater access to water by adults. Future studies need to experimentally manipulate water availability for each sex separately to determine how this affects the rate of male harassment and the fitness of females. We did not pursue this 
approach in the current study because we were primarily interested in the net effect of a natural environmental change in water availability for adults. In the wild access to water always changes for both sexes simultaneously.

\section{Female age effects}

Independently of any effect of greater exposure to males there was a reduction in both egg laying rate and egg-adult survival over time. These findings are likely to be related to maternal age (Fox, 1993). Previous studies have found that older females lay fewer, smaller eggs with reduced eclosion success (e.g. Fox 1993, but see Moore and Harris 2003), presumably due to the depletion of female breeding resources (Richards \& Myers, 1980). Surprisingly, this agerelated reduction in the number of eggs laid and their eclosion success was significantly greater for females with access to water. In general, females deprived of suitable oviposition substrate lay fewer eggs (Messina \& Fry, 2003), and egg-adult survival is reduced when host beans are of lower quality (Fox, Waddell, \& Mousseau, 1994). One explanation for our findings is therefore that, while water is beneficial for adults, it increased the humidity in the test containers reducing the quality of the beans for developing larvae, reducing egg-adult survival (e.g. growth of fungus due to high humidity) and lowering the rate of egg laying. This explanation can be tested by measuring offspring traits when reared on beans in a humid and a dry environment.

\section{Conclusions}

In C. maculatus the environment can affect the materials transferred in ejaculates, which should affect the fitness gained by females who remate, as well as the costs of male harassment for females. In our study, despite previously demonstrated effects of water availability on female fitness and male ejaculate properties, we found little evidence for a difference in the relative fitness of females housed with or without water, as there was no effect on our measure of lifetime egg production. More importantly, while being exposed to 
more males significantly reduced female lifetime fecundity this negative effect was not moderated by adult access to water. Future studies should investigate the, albeit artificial, effect of experimentally induced sex-specific changes in water availability to disentangle how this changes the costs and benefits for females of greater exposure to males. This might reveal that simultaneous changes in costs and benefits cancel out. Such a study should also be designed to tease apart the different effects of mating and resisting harassment on female fitness. In addition, it is important to explore whether the balance between the costs and benefits of male-female interactions change in more realistic and natural environments, where sexual encounters are less frequent and hence male harm is potentially reduced (e.g. Yun et al., 2017).

\section{Acknowledgements}

We thank Sam Brookes for assistance in the lab, Susi Zajitschek for help with experimental design, and Joe Tomkins for providing beetles and advise on how to look after them. This work was supported by Australian Research Council (MJ, DP160100285; MH, Future Fellowship FT160100149).

\section{REFERENCES}

Arnqvist, G., \& Nilsson, T. (2000). The evolution of polyandry: multiple mating and female fitness in insects. Animal Behaviour, 60, 145-164.http://doi.org/10.1006/anbe.2000.1446

Bateman, P. W., Ferguson, J. W. H., \& Yetman, C. A. (2006). Courtship and copulation, but not ejaculates, reduce the longevity of female field crickets (Gryllus bimaculatus). Journal of Zoology, 268(4), 341-346. http://doi.org/10.1111/j.1469-7998.2006.00054.x

Blyth, J. E., \& Gilburn, A. S. (2006). Extreme promiscuity in a mating system dominated by sexual conflict. Journal of Insect Behavior, 19(4), 447-455. http://doi.org/10.1007/s10905-006-9034-3 
Chapman, T., Liddle, L. F., Kalb, J. M., Wolfner, M. F., \& Partridge, L. (1995). Cost of mating in Drosophila melanogaster females is mediated by male accessory gland products. Nature. http://doi.org/10.1038/373241a0

Colegrave, N., Kotiaho, J. S., \& Tomkins, J. L. (2002). Mate choice or polyandry: reconciling genetic compatability and good genes sexual selection. Evolutionary Ecology Research, 4(911-917), 911-917.

Crudgington, H. S., \& Siva-Jothy, M. T. (2000). Genital damage, kicking and early death. Nature, 407, 855-856. http://doi.org/10.1038/35038154

Dadda, M., Pilastro, A., \& Bisazza, A. (2005). Male sexual harassment and female schooling behaviour in the eastern mosquitofish. Animal Behaviour, 70(2), 463-471. http://doi.org/10.1016/j.anbehav.2004.12.010

den Hollander, M. (2007). Factors affecting multiple mating by female seed beetles Callosobruchus maculatus. Toronto: University of Toronto.

den Hollander, M., \& Gwynne, D. T. (2009). Female fitness consequences of male harassment and copulation in seed beetles, Callosobruchus maculatus. Animal Behaviour, 78(5), 1061-1070. http://doi.org/10.1016/j.anbehav.2009.06.036

Dougherty, L. R., \& Simmons, L. W. (2017). X-ray micro-CT scanning reveals temporal separation of male harm and female kicking during traumatic mating in seed beetles. Proceeding of the Royal Society of London B: Biological Science, 284.

Dougherty, L. R., van Lieshout, E., McNamara, K. B., Moschilla, J. A., Arnqvist, G., \& Simmons, L. W. (2017). Sexual conflict and correlated evolution between male persistence and female resistance traits in the seed beetle Callosobruchus maculatus. Proceedings of the Royal Society B: Biological Sciences, 284(1855), 20170132.

http://doi.org/10.1098/rspb.2017.0132 
Eady, P. E., Hamilton, L., \& Lyons, R. E. (2007). Copulation, genital damage and early death in Callosobruchus maculatus. Prooceeding of the Royal Society B, 274(October 2006), 247252. http://doi.org/10.1098/rspb.2006.3710

Eady, P. E., Wilson, N., \& Jackson, M. (2000). Copulating with multiple mates enhances female fecundity but not egg-to- adult survival in the bruchid beetle Callosobruchus maculatus. Evolution, 54(6), 2161-5.

Edenbrow, M., Darden, S. K., Ramnarine, I. W., Evans, J. P., James, R., \& Croft, D. P. (2011). Environmental effects on social interaction networks and male reproductive behaviour in guppies, Poecilia reticulata. Animal Behaviour, 81(3), 551-558. http://doi.org/10.1016/j.anbehav.2010.11.026

Edvardsson, M. (2007). Female Callosobruchus maculatus mate when they are thirsty: resource-rich ejaculates as mating effort in a beetle. Animal Behaviour, 74(2), 183-188. http://doi.org/10.1016/j.anbehav.2006.07.018

Fedorka, K. M., Zuk, M., \& Mousseau, T. A. (2004). Immune suppression and the cost of reproduction in the ground cricket, Allonemobius socius. Evolution, 58(11), 2478-2485. http://doi.org/10.1111/j.0014-3820.2004.tb00877.x

Fox, C., Stillwell, R., Wallin, W., \& Hitchcock, L. (2006). Temperature and host species affect nuptial gift size in a seed-feeding beetle. Functional Ecology, 20(6), 1003-1011. http://doi.org/10.1111/j.1365-2435.2006.01197.x

Fox, C. W. (1993). The influence of maternal age and mating frequency on egg size and offspring performance in Callosobruchus maculatus (Coleoptera: Bruchidae). Oecologia, 96, 139-146.

Fox, C. W., Hickman, D. L., Raleigh, L., \& Mousseau, T. A. (1995). Paternal investment in a seed beetle (Coleoptera: Bruchidae): influence of male size, age and mating history. 
Fox, C. W., Waddell, K. J., \& Mousseau, T. A. (1994). Host-associated fitness variation in a seed beetle (Coleoptera: Bruchidae): evidence for local adaptation to a poor quality host. Oecologia, 99(3-4), 329-336. http://doi.org/10.1007/BF00627746

Gasparini, C., Devigili, A., \& Pilastro, A. (2012). Cross-generational effects of sexual harassment on female fitness in the guppy. Evolution, 66(2), 532-543. http://doi.org/10.1111/j.15585646.2011.01455.x

Gay, L., Eady, P. E., Vasudev, R., Hosken, D. J., \& Tregenza, T. (2009). Costly sexual harassment in a beetle. Physiological Entomology, 34(1), 86-92. http://doi.org/10.1111/j.13653032.2008.00656.x

Harrison, X. A. (2014). Using observation-level random effects to model overdispersion in count data in ecology and evolution. PeerJ, 2, e616. http://doi.org/10.7717/peerj.616

Hasson, O., \& Stone, L. (2009). Male infertility, female fertility and extrapair copulations. Biological Reviews, 84(2), 225-244. http://doi.org/10.1111/j.1469-185X.2008.00068.x

Hotzy, C., Polak, M., Rönn, J. L., \& Arnqvist, G. (2012). Phenotypic engineering unveils the function of genital morphology. Current Biology, 22(23), 2258-2261. http://doi.org/10.1016/j.cub.2012.10.009

Hutchinson, J. M. C., \& Halupka, K. (2004). Mate choice when males are in patches: Optimal strategies and good rules of thumb. Journal of Theoretical Biology, 231(1), 129-151. http://doi.org/10.1016/j.jtbi.2004.06.009

Iglesias-Carrasco, Jennions M. D., Zajitschek, S., \& Head, M. L. In review. Are females in good condition better able to cope with costly males?

Jennions, M. D., \& Petrie, M. (2000). Why do females mate multiply? A review of the genetic benefits. Biological Reviews, 75(1), 21-64. http://doi.org/10.1017/s0006323199005423 
474 Johnstone, R. A., \& Keller, L. (2000). How males can gain by harming their mates: sexual

475 conflict, seminal toxins, and the cost of mating. The American Naturalist, 156(4), 368377. http://doi.org/doi:10.1086/303392

Kokko, H., \& Mappes, J. (2005). Sexual selection when fertilization is not quaranteed. Evolution, 59(9), 1876-1885.

Kokko, H., \& Rankin, D. J. (2006). Lonely hearts or sex in the city? Density-dependent effects in mating systems. Philosophical Transactions of the Royal Society of London. Series B, Biological Sciences, 361(1466), 319-334. http://doi.org/10.1098/rstb.2005.1784

Martin, O. Y., \& Hosken, D. J. (2003). The evolution of reproductive isolation through sexual conflict. Nature, 423, 979-982. http://doi.org/10.1038/nature01718.1.

Messina, F., \& Fry, J. D. (2003). Environment-dependent reversal of a life history trade-off in the seed beetle Callosobruchus maculatus. Journal of Evolutionary Biology, 16(3), 501-

Messina, F., \& Slade, A. (1997). Inheritance of Host-Plant Choice in the Seed Beetle Callosobruchus maculatus (Coleoptera: Bruchidae). Annals of the Entomological Society of increase female fecundity in a seed beetle. Behavioral Ecology, 17(6), 940-946. 
Ojanguren, A., \& Magurran, A. E. (2007). Male harassment reduces short-term female fitness in guppies. Behaviour, 144(5), 503-514. http://doi.org/10.1163/156853907780713055

501

502

503

504

505

506

507

508

509

510

511

Perry, J. C., \& Rowe, L. (2010). Condition-dependent ejaculate size and composition in a ladybird beetle. Proceedings of the Royal Society B-Biological Sciences, 277(1700), 36393647. http://doi.org/10.1098/rspb.2010.0810

Plath, M., Parzefall, J., \& Schlupp, I. (2003). The role of sexual harassment in cave and surface dwelling populations of the Atlantic molly, Poecilia mexicana (Poeciliidae, Teleostei). Behavioral Ecology and Sociobiology, 54(3), 303-309. http://doi.org/10.1007/s00265003-0625-0

Polak, M., Simmons, L. W., Benoit, J. B., Ruohonen, K., Simpson, S. J., \& Solon-Biet, S. M. (2017). Nutritional geometry of paternal effects on embryo mortality. Proceedings. Biological Sciences, 284(1864), 20171492. http://doi.org/10.1098/rspb.2017.1492

Richards, L., \& Myers, H. (1980). Maternal influences on size and emergence time of the cinnabar moth. Canadian Journal of Zoology, 58, 1452-1457.

Rönn, J., Katvala, M., \& Arnqvist, G. (2006). The costs of mating and egg production in Callosobruchus seed beetles. Animal Behaviour, 72(2), 335-342. http://doi.org/10.1016/j.anbehav.2005.10.024

Rosenthal, G. G. (2017). Mate choice: the evolution of sexual decision making from microbes to humans. United Kingdom: Princeton University Press.

Rowe, L., Arnqvist, G., Sih, A., \& J.Krupa, J. (1994). Sexual conflict and the evolutionary ecology of mating patterns: water striders as a model system. Trends in Ecology \& Evolution, 9(8), 289-293. http://doi.org/10.1016/0169-5347(94)90032-9

Savalli, U. M., \& Fox, C. W. (1999). The effect of male size, age, and mating behavior on sexual 

selection in the seed beetle Callosobruchus maculatus. Functional Ecology, 13(May), 169177. http://doi.org/10.1080/08927014.1999.9522841

Sih, A., Montiglio, P. O., Wey, T. W., \& Fogarty, S. (2017). Altered physical and social conditions produce rapidly reversible mating systems in water striders. Behavioral Ecology, 28(3), 632-639. http://doi.org/10.1093/beheco/arx021

Smith, C. C. (2007). Independent effects of male and female density on sexual harassment, female fitness, and male competition for mates in the western mosquitofish Gambusia affinis. Behavioral Ecology and Sociobiology, 61(9), 1349-1358. http://doi.org/10.1007/s00265-007-0365-7

Takahashi, Y., \& Watanabe, M. (2010). Female reproductive success is affected by selective male harassment in the damselfly Ischnura senegalensis. Animal Behaviour, 79(1), 211216. http://doi.org/10.1016/j.anbehav.2009.10.032

Therneau, T., \& Grambsch, P. (2000). Modeling survival data: extending the Cox model. New York, USA: Springer.

Thornhill, R., \& Alcock, J. (1983). The evolution of insect mating systems. Cambridge, Massachusets: Harvard University Press.

Toft, S., \& Albo, M. J. (2015). Optimal numbers of matings: The conditional balance between benefits and costs of mating for females of a nuptial gift-giving spider. Journal of Evolutionary Biology, 28(2), 457-467. http://doi.org/10.1111/jeb.12581

Townsend, A. K., Clark, A. B., \& McGowan, K. J. (2010). Direct Benefits and Genetic Costs of Extrapair Paternity for Female American Crows ( Corvus brachyrhynchos ). The American Naturalist, 175(1), E1-E9. http://doi.org/10.1086/648553

Tregenza, T., \& Wedell, N. (2002). Polyandrous females avoid costs of inbreeding. Nature, 415(Table 2), 71-73. 
Ursprung, C., Den Hollander, M., \& Gwynne, D. T. (2009). Female seed beetles, Callosobruchus maculatus, remate for male-supplied water rather than ejaculate nutrition. Behavioral Ecology and Sociobiology, 63(6), 781-788. http://doi.org/10.1007/s00265-009-0711-z

Watson, P. J., Arnqvist, G., \& Stallmann, R. R. (1998). Sexual conflict and the energetic costs of mating and mate choice in water striders. American Naturalist, 151(1), 46-58. http://doi.org/10.1086/286101

Welch, A. M. (2003). Genetic benefits of a female mating preference in gray tree frogs are context-dependent. Evolution, 57(4), 883-893. http://doi.org/10.1111/j.00143820.2003.tb00299.x

Wigby, S., \& Chapman, T. (2005). Sex peptide causes mating costs in female Drosophila melanogaster. PlosBiology, 15, 316-321. http://doi.org/10.1016/j

Yamane, T., Goenaga, J., Rönn, J. L., \& Arnqvist, G. (2015). Male seminal fluid substances affect sperm competition success and female reproductive behavior in a seed beetle. PLOS ONE, 10(4), 1-14. http://doi.org/10.1371/journal.pone.0123770

Yamane, T., Miyatake, T., \& Kimura, Y. (2008). Female mating receptivity after injection of male-derived extracts in Callosobruchus maculatus, 54, 1522-1527. http://doi.org/10.1016/j.jinsphys.2008.09.001

Yun, L., Chen, P. J., Singh, A., Agrawal, A. F., \& Rundle, H. D. (2017). The physical environment mediates male harm and its effect on selection in females. Proceedings of the Royal Society B: Biological Sciences, 284(1858), 20170424. http://doi.org/10.1098/rspb.2017.0424 
Model parameter estimates and test statistics:

572 Table A1. Effect of water availability and exposure to males on the lifetime number of eggs.

573 GLM model output from full (including interaction terms) and reduced (main effects only)

574 models (see text), and statistical comparisons of model fits. Significant values are in bold.

\section{Lifetime number of eggs}

\begin{tabular}{|c|c|c|c|c|c|}
\hline \multicolumn{2}{|l|}{ 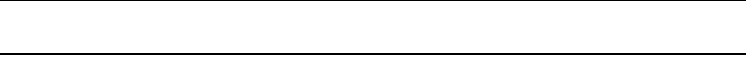 } & Estimate & Std. Error & t-value & $\mathrm{p}$ \\
\hline \multicolumn{6}{|l|}{ Full model } \\
\hline \multicolumn{2}{|l|}{ (Intercept) } & 3.939 & 0.048 & 81.16 & $<0.001$ \\
\hline \multicolumn{2}{|l|}{ Water (Yes) } & 0.129 & 0.067 & 1.93 & \\
\hline \multicolumn{2}{|l|}{ Male number (1 male) } & 0.062 & 0.068 & 0.91 & \\
\hline \multicolumn{2}{|l|}{ Male number ( 4 males) } & -0.06 & 0.071 & -0.848 & \\
\hline \multicolumn{2}{|l|}{ Water*Male number (1 male) } & -0.201 & 0.097 & -2.07 & 0.039 \\
\hline \multicolumn{2}{|l|}{ Water*Male number ( 4 males) } & -0.156 & 0.100 & -1.56 & 0.119 \\
\hline \multicolumn{6}{|l|}{ Reduced model } \\
\hline \multicolumn{2}{|l|}{ (Intercept) } & 3.997 & 0.039 & 101.73 & $<0.001$ \\
\hline \multicolumn{2}{|l|}{ Water (Yes) } & 0.015 & 0.041 & 0.38 & 0.707 \\
\hline \multicolumn{2}{|l|}{ Male number (1 male) } & -0.004 & 0.049 & -0.76 & 0.444 \\
\hline \multicolumn{2}{|l|}{ Male number (4 male) } & -0.139 & 0.050 & -2.77 & 0.006 \\
\hline \multicolumn{6}{|l|}{ Comparison of fit } \\
\hline Model & $\begin{array}{l}\text { Residual } \\
\text { (df) }\end{array}$ & $\begin{array}{l}\text { Residual } \\
\text { deviance }\end{array}$ & Deviance & $\mathrm{F}$ & $\mathrm{p}$ \\
\hline Full & 271 & 1830.9 & & & \\
\hline Reduced & 273 & 1859.1 & -28.194 & 2.378 & 0.095 \\
\hline \multicolumn{6}{|l|}{575} \\
\hline $\begin{array}{l}\text { Table A2. Effect of water a } \\
\text { rate of egg laying. GLMM } \\
\text { (main effects only) models } \\
\text { are in bold. }\end{array}$ & $\begin{array}{l}\text { ability and e } \\
\text { el outputs } f \\
\text { statistical }\end{array}$ & $\begin{array}{l}\text { xposure to } \\
\text { om full (inc } \\
\text { omparison }\end{array}$ & $\begin{array}{l}\text { nales, as wel } \\
\text { uding intera } \\
\text { of model fits }\end{array}$ & $\begin{array}{l}\text { s days since } \\
\text { on terms) a } \\
\text { ee text). Sig }\end{array}$ & $\begin{array}{l}\text { ting on } \\
\text { educed } \\
\text { :ant values }\end{array}$ \\
\hline
\end{tabular}

Rate of egg laying

\begin{tabular}{lrrrr}
\hline & Estimate & Std. Error & z-value & \multicolumn{1}{c}{$p$} \\
\hline Full model & & & & \\
(Intercept) & 2.741 & 0.06 & 45.62 & $<0.001$ \\
Water (yes) & 0.103 & 0.085 & 1.21 & \\
Male number (1 male) & -0.005 & 0.086 & -0.05 & \\
Male number(4 males) & 0.017 & 0.087 & 0.19 & \\
Day 3 & -0.219 & 0.075 & -2.92 & \\
Water * Male number (1 male) & -0.152 & 0.123 & -1.24 & 0.216 \\
Water * Male number (4 males) & -0.179 & 0.123 & -1.46 & 0.144 \\
Water * Day 3 & -0.232 & 0.108 & -2.15 & $\mathbf{0 . 0 3 2}$ \\
Male number (1 male) * Day 3 & 0.019 & 0.107 & 0.18 & 0.854
\end{tabular}




\begin{tabular}{lrrrr} 
Male number (4 males) * Day 3 & -0.008 & 0.108 & -0.07 & 0.941 \\
Water * Male number (1 male) * Day 3 & 0.139 & 0.155 & 0.90 & 0.368 \\
Water * Male number (4 males) * Day 3 & 0.048 & 0.156 & 0.31 & 0.759 \\
Reduced model & & & & \\
(Intercept) & 2.816 & 0.043 & 65.62 & $<0.001$ \\
Water (yes) & -0.084 & 0.041 & -2.04 & $\mathbf{0 . 0 4 2}$ \\
Male number (1 male) & -0.039 & 0.049 & -0.78 & 0.433 \\
Male number (4 males) & -0.064 & 0.052 & -1.28 & 0.199 \\
Day 3 & -0.298 & 0.032 & -9.17 & $<0.001$ \\
\hline
\end{tabular}

\section{Comparison of fit}

\begin{tabular}{lrrrrr} 
Model & df & $\begin{array}{c}\text { Log- } \\
\text { likelihood }\end{array}$ & Deviance & X2 & p \\
\hline Full & 7 & 3649.2 & -1802.5 & & \\
Reduced & 14 & 3681.7 & -1796.6 & 11.73 & 0.109
\end{tabular}

581 Table A3. Effect of water availability, exposure to males and days since mating on the 582 percentage of eggs emerging as adults. GLMM model outputs from full models (including 583 interaction terms). Significant values are in bold.

\section{Egg to adult survival (i.e. eggs emerging as adults, \%)}

\begin{tabular}{lrrrr}
\hline & Estimate & Std. Error & z-value & $\mathrm{p}$ \\
\hline Full model & & & & \\
(Intercept) & 2.752 & 0.173 & 15.87 & $<0.001$ \\
Water (yes) & -0.892 & 0.225 & -3.97 & \\
Male number (1 male) & -0.331 & 0.239 & -1.39 & \\
Male number (4 males) & -0.407 & 0.238 & -1.71 & \\
Day 3 & -0.054 & 0.206 & -0.26 & \\
Day 4 & -1.270 & 0.159 & -8.04 & \\
Water*Male number (1 male) & -0.157 & 0.314 & -0.50 & 0.617 \\
Water*Male number (4 males) & -0.361 & 0.311 & -1.16 & 0.246 \\
Water*Day 3 & -0.336 & 0.256 & -1.31 & 0.191 \\
Water*Day 4 & $\mathbf{0 . 7 3 8}$ & $\mathbf{0 . 2 0 0}$ & $\mathbf{3 . 6 8}$ & $<0.001$ \\
Male number (1 male)*Day 3 & -0.101 & 0.276 & -0.37 & 0.714 \\
Male number (4 males)*Day 3 & -0.089 & 0.275 & -0.32 & 0.747 \\
Male number (1 male)*Day 4 & 0.236 & 0.217 & 1.09 & 0.278 \\
Male number (4 males)*Day 4 & -0.053 & 0.102 & -0.52 & 0.605 \\
Water*Male number (1 male)*Day 3 & 0.557 & 0.349 & 1.59 & 0.111 \\
Water*Male number (4 males)*Day 3 & $\mathbf{0 . 9 3 9}$ & $\mathbf{0 . 3 4 7}$ & $\mathbf{2 . 4 2}$ & $\mathbf{0 . 0 1 6}$ \\
Water*Male number (1 male)*Day 4 & 0.247 & 0.281 & 0.88 & 0.379 \\
Water*Male number (4 males)*Day 4 & $\mathbf{0 . 9 5 9}$ & $\mathbf{0 . 2 7 9}$ & $\mathbf{3 . 4 4}$ & $\mathbf{0 . 0 0 1}$
\end{tabular}

Table A4. Effect of water availability, exposure to males, and days since mating on offspring 586 development time. GLMM model outputs from full (including interaction terms) and reduced 587 (main effects only) models, and statistical comparison of model fits (see text). Significant 588 values are in bold. 
Egg development time (days)

\begin{tabular}{|c|c|c|c|c|}
\hline & Estimate & Std. Error & z-value & $p$ \\
\hline \multicolumn{5}{|l|}{ Full model } \\
\hline (Intercept) & 3.237 & 0.028 & 114.3 & $<0.001$ \\
\hline Water (yes) & 0.003 & 0.04 & 0.08 & \\
\hline Mating ( 1 male) & 0.006 & 0.04 & 0.14 & \\
\hline Mating (4 males) & 0.002 & 0.041 & 0.05 & \\
\hline Day 3 & -0.001 & 0.040 & -0.02 & \\
\hline Day 4 & -0.002 & 0.040 & -0.06 & \\
\hline Water*Male number ( 1 male) & -0.004 & 0.058 & -0.07 & 0.948 \\
\hline Water*Male number ( 4 males) & 0.011 & 0.058 & 0.19 & 0.85 \\
\hline Water*Day 3 & 0.003 & 0.057 & 0.06 & 0.952 \\
\hline Water*Day 4 & -0.017 & 0.057 & -0.29 & 0.769 \\
\hline Male number ( 1 male)*Day 3 & -0.004 & 0.057 & -0.07 & 0.947 \\
\hline Male number (4 males)*Day 3 & -0.007 & 0.058 & -0.12 & 0.901 \\
\hline Male number (1 male)*Day 4 & -0.018 & 0.057 & -0.32 & 0.747 \\
\hline Male number ( 4 males)*Day 4 & -0.013 & 0.058 & -0.22 & 0.826 \\
\hline Water*Male number ( 1 male)* Day 3 & 0.006 & 0.083 & 0.07 & 0.945 \\
\hline Water*Male number (4 males)*Day 3 & -0.009 & 0.083 & -0.12 & 0.907 \\
\hline Water* Male number ( 1 male)*Day 4 & 0.019 & 0.083 & 0.24 & 0.813 \\
\hline Water*Male number ( 4 males)*Day 4 & 0.009 & 0.083 & 0.11 & 0.909 \\
\hline \multicolumn{5}{|l|}{ Reduced model } \\
\hline (Intercept) & 3.239 & 0.017 & 193.94 & $<0.001$ \\
\hline Water (yes) & 0.004 & 0.014 & 0.27 & 0.784 \\
\hline Mating (1 male) & 0.001 & 0.017 & 0.03 & 0.974 \\
\hline Mating (4 males) & 0.001 & 0.017 & 0.04 & 0.965 \\
\hline Day 3 & -0.003 & 0.017 & -0.2 & 0.839 \\
\hline Day4 & -0.162 & 0.017 & -0.96 & 0.338 \\
\hline Comparison of fit & $\begin{array}{c}\text { Log- } \\
\text { likelihood }\end{array}$ & Deviance & $x^{2}$ & $\mathrm{p}$ \\
\hline \multicolumn{5}{|l|}{ Model } \\
\hline Full & -2079.1 & 4158.1 & & \\
\hline Reduced & -2078.8 & 4157.7 & 0.4516 & 1 \\
\hline
\end{tabular}

594

Female survival (days)

\begin{tabular}{lcccc} 
& Coefficient & Std.Error (coef) & $\begin{array}{c}z- \\
\text { value }\end{array}$ & $p$ \\
\cline { 2 - 5 } Full model & -0.296 & 0.069 & -4.31 & $<\mathbf{0 . 0 0 1}$
\end{tabular}




\begin{tabular}{lcccc} 
Male number (1 male) & 0.007 & 0.063 & 0.11 & 0.91 \\
Male number (4 males) & 0.094 & 0.062 & 1.51 & 0.13 \\
Water*Male number (1 male) & 0.067 & 0.097 & 0.68 & 0.49 \\
Water*Male number (4 males) & 0.016 & 0.096 & 0.17 & 0.87 \\
\hline Reduced model & & & & \\
Water (yes) & -0.269 & 0.039 & -6.82 & $<0.001$ \\
Male number (2 males) & 0.035 & 0.048 & 0.72 & 0.469 \\
Male number (4 males) & 0.1 & 0.047 & 2.11 & 0.035 \\
\hline Comparison of fit & & & & \\
Model & loglik & $\chi^{2}$ & $\mathrm{df}$ & $\mathrm{p}$ \\
Full & -18201 & & & \\
Reduced & -18201 & 0.51 & 2 & 0.775 \\
\hline
\end{tabular}

595

Figure 2. Percentage of emerging adults (egg-adult survival) in each of the three days after

Figure 1. a) Total number of eggs, and b) number of eggs laid by females on each of the two days after copulation in relation to the exposure to males $(0,1,4$ males) and the water treatment (dry, wet) (D0: dry, no males; W0: wet, no males; D1: dry, one male; W1: wet, one male; D4: dry, four males; W4: wet, four males) (Mean \pm SE).

608

609

Figure 3. Time for offspring development for each of the four days after female copulation in relation to the mating and water treatments (Mean $\pm \mathrm{SE}$ ).

Figure 4. Kaplan-Meier survival plots for females maintained in dry or wet conditions. There are differences in female survival in relation to water availability, but not of male number nor any interaction between the two treatments (see text). 


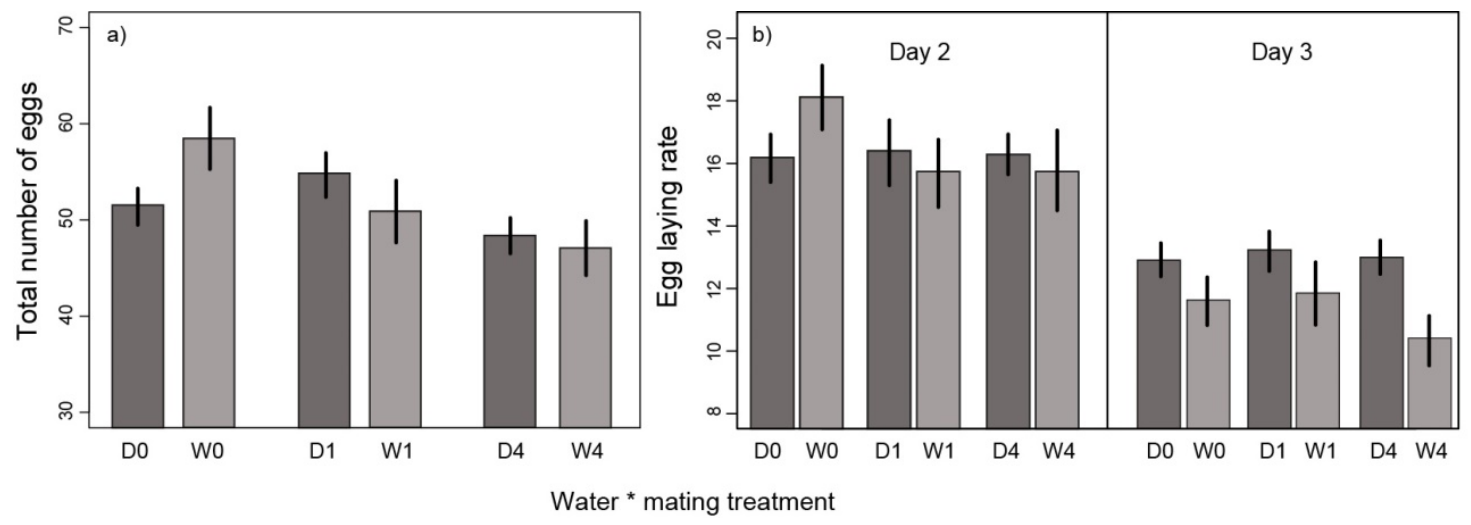

624

$625 \quad$ Fig 2

626

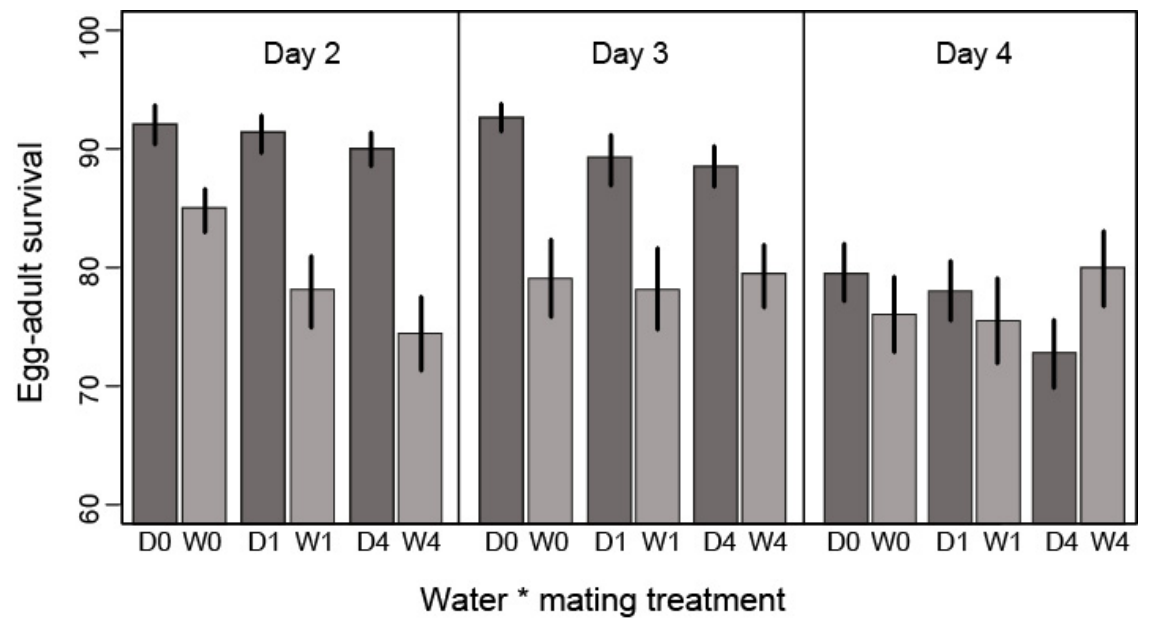

627

628

\section{Fig 3}

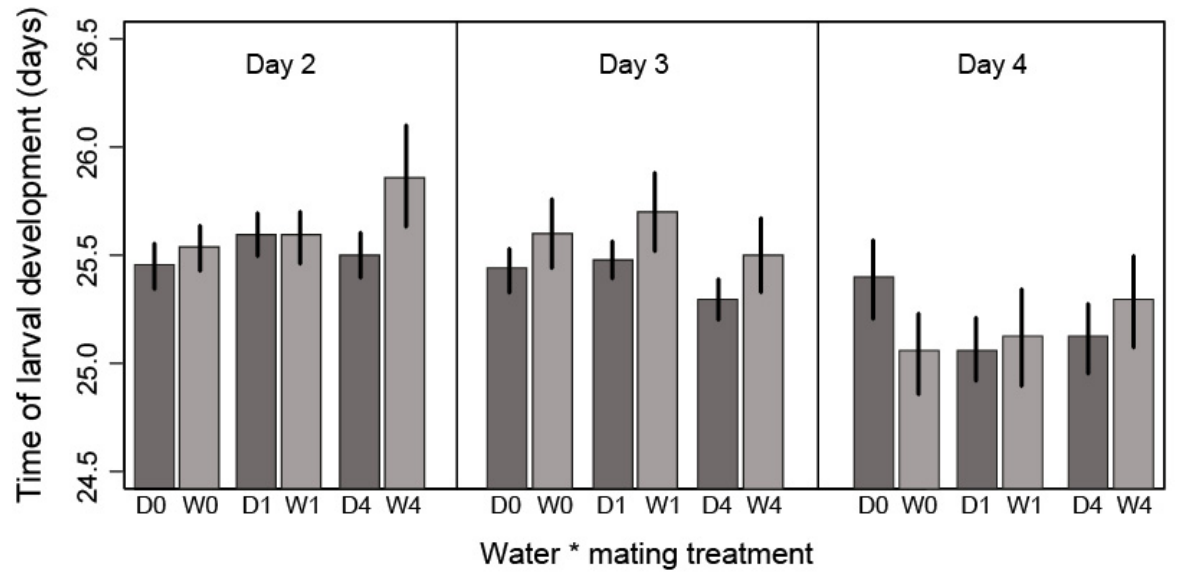

629

630

Fig 4 


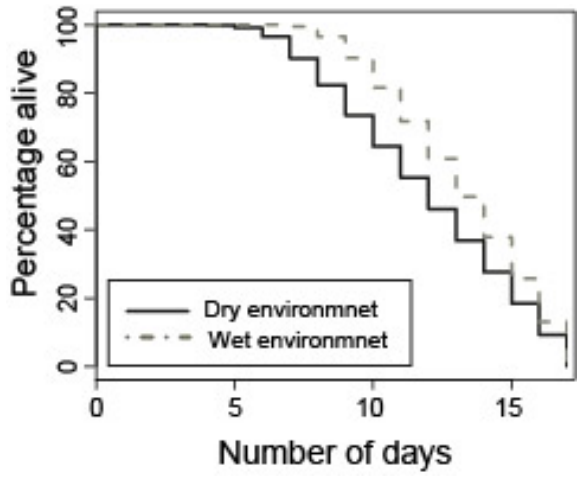

631

632

633

634 